\title{
Solid phase synthesis of calcium stearate on a modified screw equipment
}

\author{
(C) Alexander A. Momziakov, ${ }^{1+}$ Timur R. Deberdeev, ${ }^{1}$ Railya F. Nafikova ${ }^{3}$ \\ Eugeny A. Pecheny, ${ }^{2}$ Nail K. Nuriev, ${ }^{2}$ and Rustam Ya. Deberdeev ${ }^{1}$ * \\ Department of Technology of Processing of Polymers and Composite Materials; ${ }^{2}$ Department of \\ Informatics and Applied Mathematics. Kazan National Research Technological University. Karl Marx St., \\ 72. Kazan, 420015. Republic of Tatarstan. Russia. Phone: +7 (843) 231-42-59. E-mail: alex-m-v@yandex.ru \\ ${ }^{3}$ Department of General Chemical Technology. Ufa State Oil Technical University. \\ May Day St., 14. Ufa, 450000. Republic. Bashkortostan. Russia.
}

\begin{abstract}
*Supervising author; ${ }^{+}$Corresponding author Keywords: solid-phase synthesis, calcium stearate, optimization of experimental conditions, modified screw apparatus, full factorial experiment, heterogeneous heterophase reactions, topochemical reactions.
\end{abstract}

\begin{abstract}
Metal stearates are widely used in various industries: as a thickener, lubricants, auxiliary desiccant, emulsifier for cosmetics, chemical additives to synthetic rubbers and a stabilizing component in polyolefins (PE, PP), ABS plastic, polystyrene, polyamide and polyvinyl chloride (PVC). The greatest interest in using the metal salt of stearic acid is stabilization of PVC. At present, technologies for the synthesis of divalent metal carboxylates have evolved in three directions: synthesis technology in solution, in the melt and in the solid phase. The latter was the most laborious at the end of the last century due to the lack of equipment that allowed the imposition of mechanical energy on the material in sufficient quantity to initiate chemical transformation. In the literature, experiments are carried out on planetary mills, attritors, rollers and Bridgman anvils. In devices of a similar design, the best conditions for the chemical process between the components of the reaction mixture are created. The chemical reaction proceeds as a result of the creation and subsequent relaxation of the stress field when applying a mechanical action to the reaction mixture. However, they did not give a high selectivity for the target product; therefore, the chemical industry of stabilizing additives focused on solution methods for producing metal carboxylates. The authors of the article have developed a new approach for the synthesis of calcium stearate in the solid phase on a modified screw apparatus. Screw machines, in turn, provide an increase in the number of contacts between reagents and, more significantly, the area of the contact interface. In addition, heat generation due to friction in the contact area can further intensify the process. The influence of the temperature range inside the material cylinder - the reactor, the screw rotation speed on the technical characteristics and the yield of calcium stearate was investigated. Mathematical processing of the results of the full factorial experiment was carried out. A comparison of the adequacy of the obtained linear equation and experimental data is carried out.
\end{abstract}

\section{References}

[1] K.S. Minsker, G.T. Fedoseeva. Destruction and stabilization of polyvinyl chloride. Moscow: Chemistry. 1972. (russian)

[2] K.S. Minsker, V.P. Malinska. On the kinetics of the autocatalytic dehydrochlorination reaction of polyvinyl chloride. Vysokomolek. Comm. A. 1970. Vol.12. No.5. P.1151. (russian)

[3] Patent of the Russian Federation No. 2029759. The method of obtaining salts of unsaturated carboxylic acids and mixtures thereof. 1995. (russian)

[4] Patent of France No.1143139. Claims 1957, Publ. RJ Chem., 1960. No.8, 31483.

[5] A.S. USSR No.174615. Claims 1965; Publ. 1965, Bull. No.13. (russian)

[6] Patent of Great Britain No. 1136884. Cl. C07C51/52. Claims 1968.

[7] Japanese Patent No. 13302. Cl. C08C 65/30. 1982.

[8] The USSR AS No. 979326, MKI S07C51/41; Claims 1982; publ. 1982, Byul. No.4. (russian)

[9] AS of the USSR No. 487872, MKI S07C51/2; Claims 1973; publ. 1975, Bull. No.38. (russian)

[10] AS of the USSR No. 413854, MKI S08S27/08; Claims 1978 (unpublished). (russian)

[11] AS USSR № 601276, MKI S07S51/52; Claims 1975; publ. 1978, Byul. No.13. (russian)

Kazan. The Republic of Tatarstan. Russia.

(c) Butlerov Communications. 2019. Vol.58. No.4. 
[12] Patent of Russia No. 2087460. MKI C07 from 51/41. The method of obtaining stabilizers "SINSTAD" for polymers and its variants., Appl. 1995; Publ. 1997, Byul. No.23. (russian)

[13] B.I. But, Yu.L. Zotov. Multifunctional compositions "SINSTAD" for polymers. Plastics. 2000. No.6. P.34-35. (russian)

[14] AS of the USSR No. 404345, MKI S07C51/42; Claims 1980 (unpublished). (russian)

[15] Japanese Patent No. 4272418, Cl. C07 from 53/126. Claims 1979.

[16] Patent of the Russian Federation No. 2124495, MKI S07C51/41. Claims 1997; publ. 1999, Byul. No.1. (russian)

[17] Patent of the Russian Federation No. 2156758, MKI S07C51/41. Claims 1999; publ. 2000, Byul. No.27. (russian)

[18] B.N. Gorbunov, A.Ya. Gurvich, I.P. Maslova. Chemistry and technology of stabilizers of polymeric materials. Moscow: Chemistry. 1981. 368p. (russian)

[19] R.F. Nafikova. One-step synthesis of stearates of divalent metals: dis ... Cand. those. sciences. Sterlitamak. 2001. 176p. (russian)

[20] Patent of the Russian Federation No. 2259993, MKI S07C51/41. Claims 2004; publ. 2005 Byul. No.27. (russian)

[21] A.A. Zharov, N.P. Chistotina. Chemical Transformations of Solid Acrylamide under Deformation Conditions Under a Pressure of 8 GPa. Dokl. Academy of Sciences of the USSR. 1988. Vol.299. P.11581160. (russian)

[22] A.A. Momzyakov, R. Ya. Deberdeev. Study of the laws of solid-phase synthesis of metal stearates. Chemical Physics. 2019. Vol. 38. No.2. P.1-7. (russian)

[23] Solid-phase synthesis technology for thermostabilizers of polyvinyl chloride (PVC). Momzyakov A.A., Yakovlev I.D., Fadeeva K.S., Mustafin T.N., Deberdeev T.R. VII All-Russian Kargin Conference "Polymers-2017". Moscow. 2017. P.154-155. (russian)

[24] E.A. Stepanov, P.P. Purygin, and A.O. Chunaev. Peptide synthesis. Part 2. Getting some potentially biologically active tripeptides, through solid-phase synthesis. Butlerov Communications. 2010. Vol.19. No.1. P.17-24. ROI: jbc-02/10-19-1-17

[25] N.V. Chukanov, S.A. Popov, and V.A. Reznikov. Sold-phase synthesis of trisubstituted derivatives of isoxazoles. Butlerov Communications. 2008. Vol.13. No.3. P.7-10. ROI: jbc-02/08-13-3-7

[26] E.V. Markova, Yu.V. Granovsky. Adler Planning an experiment in the search for optimal conditions [Text]. Moscow: Science. 1976. 278p. (russian) 